\title{
Review of Power Quality Issues and Mitigation Techniques in Electrical Power Systems
}

\author{
SK.Abdul Pasha ${ }^{1}{ }^{2}$ N.Prema kumar ${ }^{2}$ \\ ${ }^{1}$ Assistant Professor, Dept. of EEE, Anurag Engg. College (A), Kodad, Telangana, India. \\ ${ }^{2}$ Professor, Dept.of Electrical Engineering, Andhra University College of Engineering (A), Vishakhapatnam, India. \\ labdulpsh@gmail.com \\ ${ }^{2}$ premnavuriegmail.com
}

\begin{abstract}
Power quality complications are treated as interrupted voltage, current or frequency which reflects as malfunction of connected elements at end levels. User system models, smoothen loads of industries and crucial, regular operations of all effected by kinds of outcomes \& line distortions, they can impact with economy of the whole system. Here the power quality includes the enhancement of voltage quality, source power factor, control of harmonic distortions, voltage sags and swells. The devices selected for power quality improvement are DSTATCOM, Hybrid active power filters, Dynamic voltage restorers, static var compensators TVSS,CVT etc.
\end{abstract}

Keywords - Power quality issues, voltage sag, Hybrid active power filters, DSTATCOM, DVR, SMES.

\section{INTRODUCTION}

For popularly forcing demands at genuinely measures, flexible outcomes and growing multiple cases of effective loads may reflects to raised awake for quality of power from users and utilities. Usual cases of PQ-dissimilarities are sags, swells, distortions in harmonics and minimal p.f [1].

Sag can be a least time (10-msec to 1-min) procedure for which drop in RMS-voltage value happens [2].Its value ranges (10-90) \% of base voltage and its period from half a cycle to one min.Sag is effected from a fault in utility system, a fault inside user facility or huge increase of load current, just like motor-starting or energising of a transformer. These are one of the usual happening issues of power quality. In industries voltagesags expectancy is often, effects with critical issues. User side regularly impacts with distortions of user end devices treated as saviour PQ-issues [3].

Swells and rise in voltages will reflects as more heating, tripping as well as malfunction of industry elements such as rotating devices. Electronic devices are more smoothen towards harmonics because its control depends on peak-value or 0-crossing of voltage supplied; these are all affected by HD [4]. Improvement of PE devices such as FACTS \& custom cases will be introduced and innovative models of giving power systems.

Hybrid Active Power filter (HAPF) models are designed with active \& passive elements in line or shunt been suggested, targeten to hike compensation capabilities of PPFs and diminishes voltage \& current ratings of APF's, like wise it leads to improve its performance. This topologies consists of lots of passive elements like transformers, capacitors, reactors and resistors. By that increases its area and cost for whole system [5-8].

\section{POWER QUALITY ISSUES}

Recent survey by experts of power quality denotes that half of all PQ-related complications be due to grounding \& its bonds N-G: Voltages, loops, GND-currents and other related issues. Following symptoms are observed for PQ's. it.

- Mis-operation of equipments on the same day.

- Trip/Brakings without any loading.

- Control apparatus stops without any reason.

- Electronic equipments fails to work for frequent basis.

- Equipment functions in one place \& malfunctions at other.

Problems of PQ are getting significance due to these reasons.

$\checkmark$ Communities being gradually dependent for electricity. Little shortages of power be a big economic impact for industry users. A longer distortion effects regularly for all tasks of developed community levels.

$\checkmark$ Invention of latest PE-equipments like VSD's and SMPS come towards another more distortions in supply system.

In order to avoid problems listed above, latest equipments introduced here as,

Line-Voltage-Regulators

$>$ Tap changers 


\section{International Journal of Engineering Technology and Management Sciences[IJETMSS]}

Website: ijetms.in Issue:5, Volume No.4, September-2020 DOI: 10.46647/ijetms.2020.v04i05.021

$>$ Buck-Boost-Regulators

$>$ Constant-Voltage-Transformers

$>$ Motor-Generator-Sets

$>$ Static-Var-Compensators

$>$ Un-Interrupted-Power-Supplies

$>$ Super-Conducting-Magnetic-Energy-Storages

$>$ Static-Transformer-Switches

$>$ Fuel-Cell-Based-Inverter-Systems

\section{SOLUTIONS TO PROBLEMS OF P-Q}

Elimination of problems of PQ will undergoes at various modules of sending and receiving end equipments which are shown below.

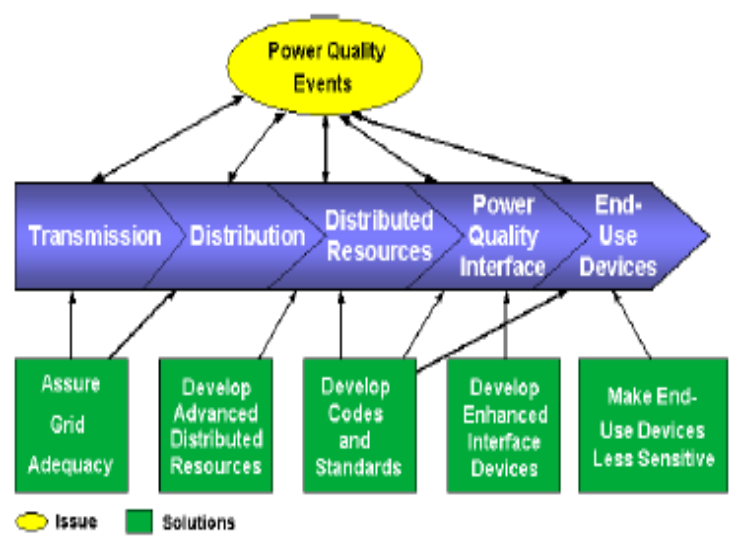

Fig. 1. PQ-Solutions approach

\section{Adequate Grids}

So many issues of $\mathrm{P}-\mathrm{Q}$ be beginner at sending or receiving ends. Likewise suitable transmission-Distribution grids with proper design, maintenances are needed to limit the happening of these issues of P.Q.

\section{Distributed Energy Resources}

Motivation towards the implementation of DER's leads to increase in sustainability for the last some decades due to its capability for making reliable coordination. Such sources add energy-storage systems at distributed levels. It also calls for compensating technologies, which will be utilized for providing capability levels for such load arrangements even though at least cases of PQenvironment. Advanced methodologies in power electronics and compensation strategies are turn to innovative keys for suppressing such difficulties in P-Q.

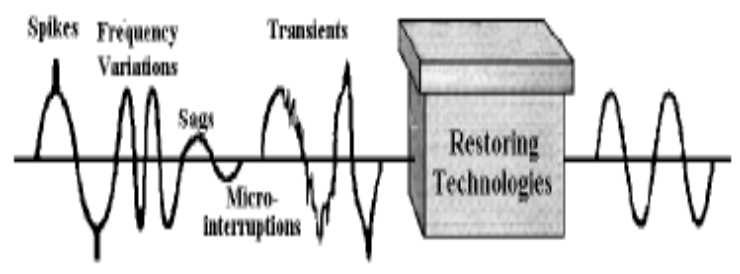

Fig. 2.Compensating models

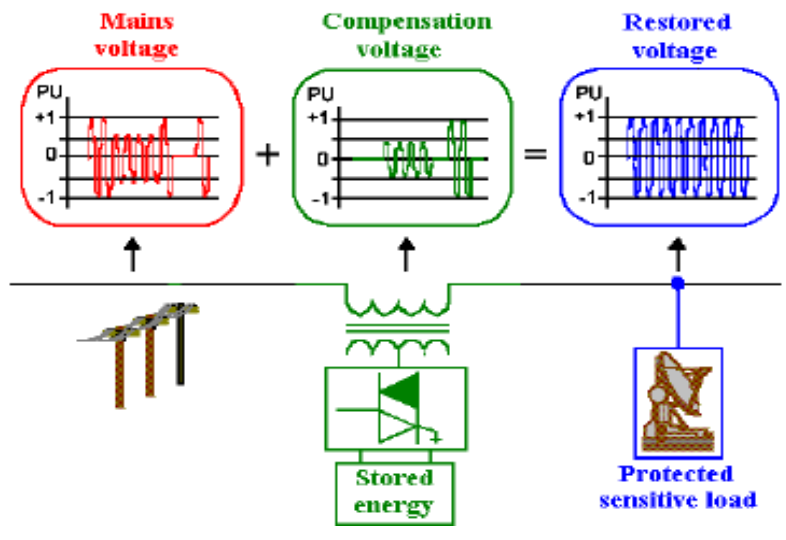

Fig. 3. Energy Storage Model

\section{A.Flywheels}

It is basically an electro-mechanical model which adds to running machineries through revolving weight to energy storage model at limited intervals. Revolving element undergoes energy offered by GND for making rotor of FWspinning. At a distributed level KE pressure at rotor shifted to DC electricity by a generator and received energy at a fixed oscillations and potential via DC-AC converter and modulated blocks.

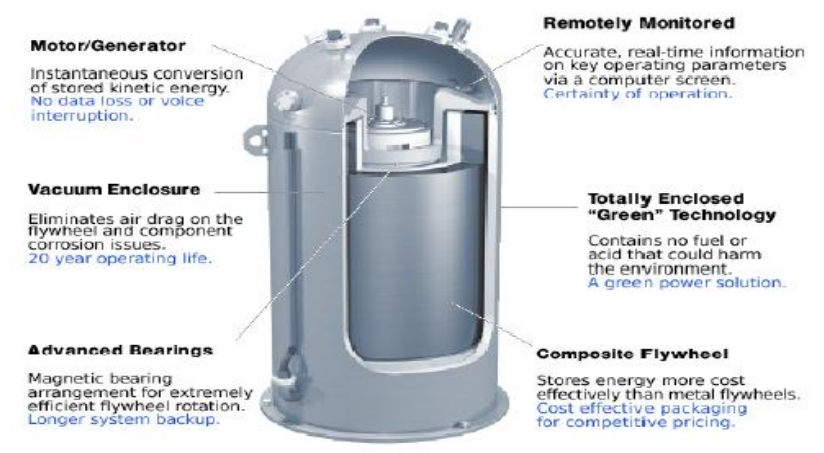

Fig. 4. Flywheel 


\section{International Journal of Engineering Technology and Management Sciences[IJETMS]}

Website: ijetms.in Issue:5, Volume No.4, September-2020 DOI: 10.46647/ijetms.2020.v04i05.021

\section{B. Double Layer Super Capacitors}

These are also known as Ultra-Capacitors, which are of dc energy abundants, which should be tied to grid with fixed conditioners, supplying output energy for the frequency of grid.

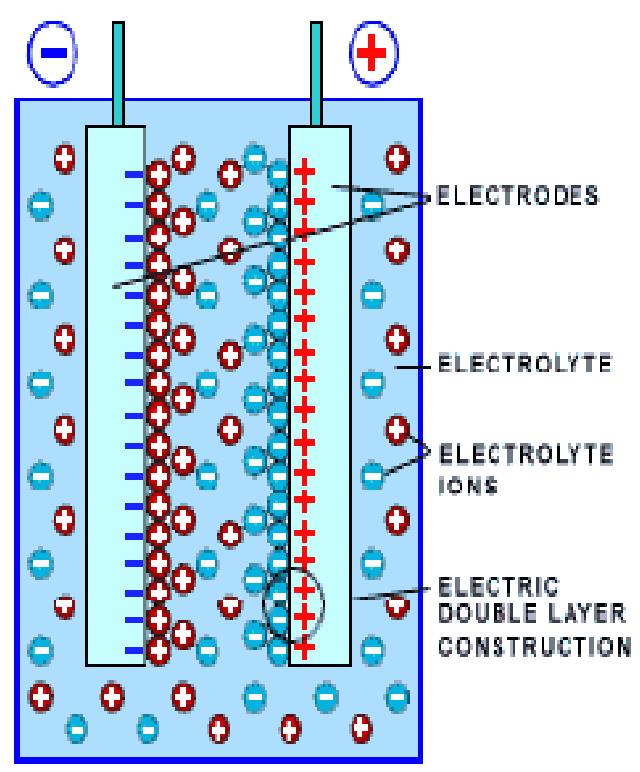

Fig. 5. Electric double layer super capacitor

\section{Superconducting Magnetic Energy Storage Systems}

It will backs up energy in flux manner, designed by pass of direct current into a extreme running coil. These are longer, usually considered for small intervals like user processing modules.

\section{ENHANCED INTERFACE MODELS}

Behind of the backup elements, D.G's, other equipment will consider for resolving PQ-complications. By using suitable tying elements we can separate loads from distortions getting from grid.

\section{A.Dynamic-Voltage-Restorer}

It behaves as a source voltage given in line through the load. Response voltage of D.V.R is set nearly constant Voltage at the load points by considering a step up transformer or compensating energy for spreading P \& Q's at receiving end side through a voltage converter.

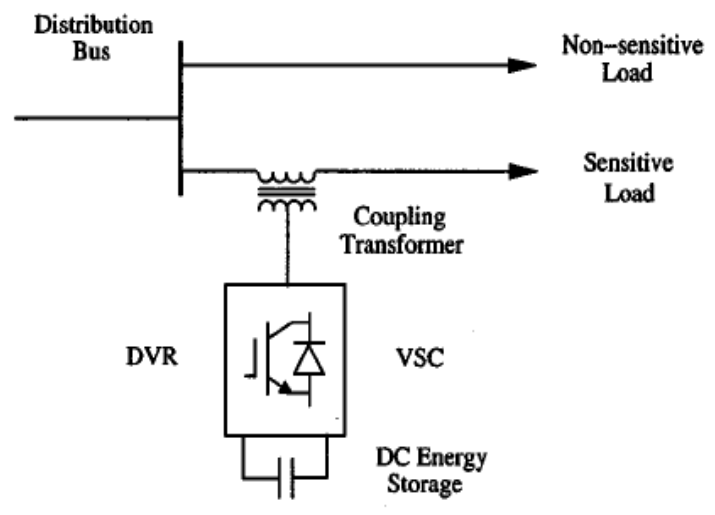

Fig. 6. Dynamic-Voltage Restorer

\section{B. Transient-Voltage-Surge-Suppressors}

These are introduced like a mediator among power input to smoother outputs, for that trans-voltage be covered by TVSS before it strikes the end point. These are likely to be having a element with a non-linear resistance (MOV/ZD) which avoids over whelming voltages and undergoes excessive energy impulses to GND.

\section{Constant-Voltage-Transformers}

These are treated as starting resolutions of PQ-issues utilized for mitigating sags \& transient-levels. For maintaining constant voltage it uses 2 fundamental basis which are usually rejected: Saturation of core and resonance.

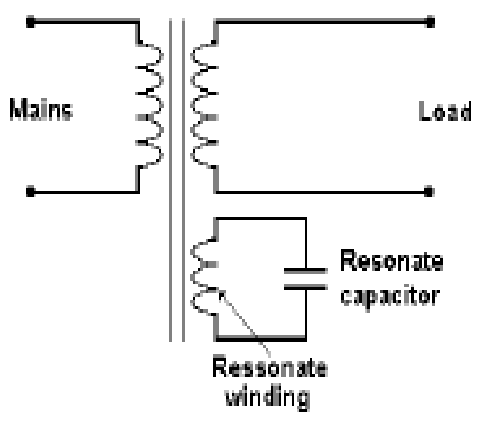

Fig. 7. Constant Voltage-Transformer

If resonance takes place current goes high to level which effects as saturation of core of magnetic for a transformer. If it is saturated then flux will be remains marginally fixed and the transformer will gives set value of response for voltage.

Improper utilization of CVT leads to excessive problems of PQ than whom ones suppressed. By that it will generates transient-harmonics which will be ineffective ( 80 


\section{International Journal of Engineering Technology and Management Sciences[IJETMIS]}

Website: ijetms.in Issue:5, Volume No.4, September-2020 DOI: 10.46647/ijetms.2020.v04i05.021

percent of full load).Its usage becomingly commonless because technical growths at some other locations.

\section{Isolation-Transformers}

Which will be implemented for for isolating smoothening loads from transient levels, interruptions drawing from supply mains. Further levels it keeps current harmonics produced by loads from obtaining top stream of the transformer. Selectivity of these transformers be a GND shield design of non-magnetic foils situated in midst of primary-secondary. Any distortion or transient which comes from input is spread via capacitance between primary \& shield on the GND, will not reaches the end point.

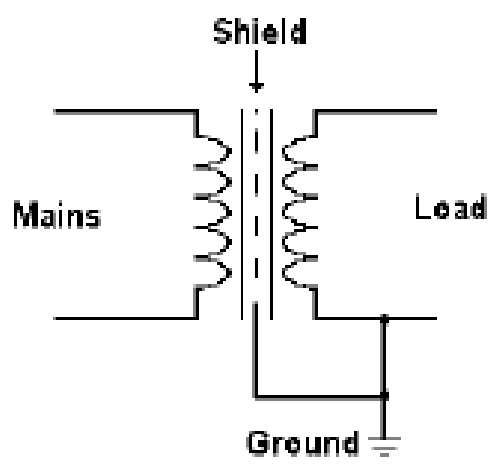

Fig. 8. Isolation-Transformer

\section{E. Static-VAR-Compensators}

It uses mix of reactors and capacitors for regulating potential immediately. Abundant-state of control switches alters the fixing of capacitor-reactors at suitable value for avoiding voltage from fluctuations.Main consideration of SVAR is to regulate voltage in peak levels and removing of flickers effected by big-loads.(ex:Induction furnaces).

\section{F. Hybrid Active power Filters}

HAPF's will be opted for reducing un necessary harmonics. These are sub divided as collectives of passive $\&$ active filters. Passive filters exits at minimal-impedance way to the frequencies of harmonics will be attenuate choosing components of passive (L, C, and R).Most of p.f's tied in shunt will be ready to diminish lot more harmony contents. If the model changes (H-components), passive filters will be in-efficient, which effects with resonance. Active-filters briefs about consumption of currents from loads and creates a magnitude which cancels $\mathrm{I}_{\mathrm{H}}$ produced by loadings.AF's are more economical in previous, but those are be cost efficient, mitigating to not known or varying harmonies.
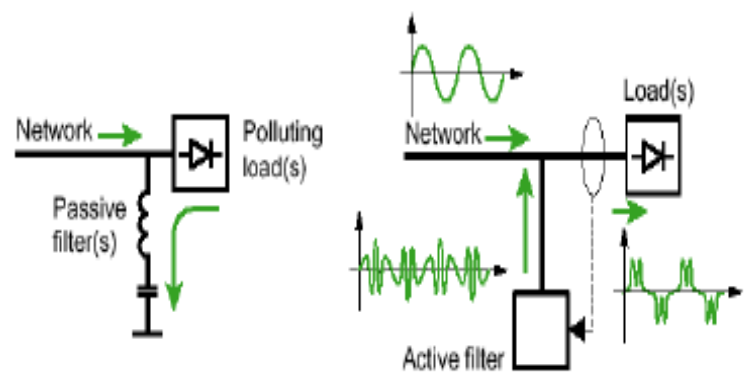

Fig. 9. Hybrid active power filters

\section{G.D-STATCOM}

Its task is to control the bus-voltage by grabbing or producing reactive power to the network like a thyristorstatic-compensator. It consists of an energy storage circuit, voltage source converter, LCL-passive-filter and controller. Energy storage circuit consists of a dc source which will be tied in line with dc capacitor.

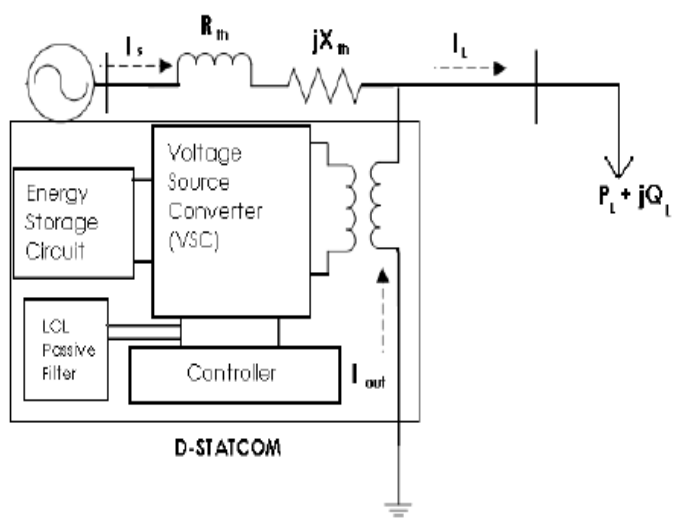

Fig. 10. Schematic diagram of a D-STATCOM

'DSTATCOM' weights source-ripple-current of converter and it is the main reactive energy storage element.DC capacitor will be energized a backup or recharged by converter itself.VSI be a PE-element which connects in shunt/parallel to the system. It will generate a sin-voltage with required value, frequency $\&$ ph-angle.VSC processed to wholly refix the voltage or to impose the un-seen voltage. It will be the difference between voltage and its actual value. It also changes dc voltage across storage devices to a set of 3-ph ac output voltages.

LCL-passive filter is most beneficent on diminishing harmonic-distortions. Controller used in this method is PIC.It runs the system to be under control aided signal error and integral of such value. For this case PIC will processes error-signal to ' 0 '.RMS-load voltage is brings back to referral voltage by comparing ref-voltage 


\section{International Journal of Engineering Technology and Management Sciences[IJETMIS]}

Website: ijetms.in Issue:5, Volume No.4, September-2020 DOI: 10.46647/ijetms.2020.v04i05.021

with RMS-voltages which had been evaluated at load point. Here we analyzed about PQ-complications and its consequences for electrical equipments. To which altered models been proposed. By the result we may rectifies the complexities.

\section{H. Unified Power Quality Conditioner}

Unified Power Quality Conditioner (UPQC) is a one of the FACTS control device. It will be designed with Shunt and Series active power filters followed by one of the DC-link capacitor.

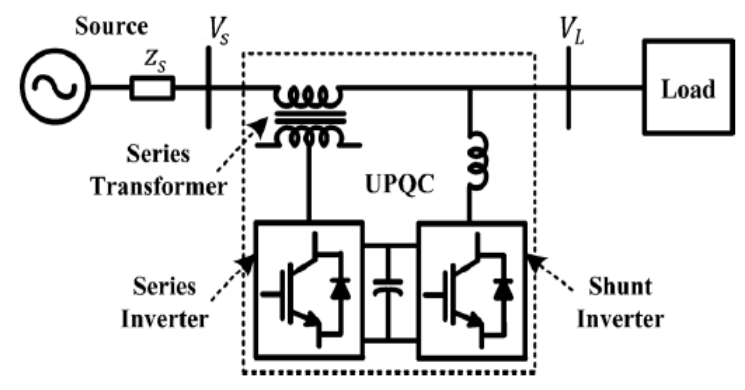

Fig. 11. Unified Power Quality Conditioner

The main blocks of UPQC are follows here,

\section{Series-Active-Power-Filter}

SE-APF is a VSI tied in series to AC-line via series transformer and behaves as a voltage-source to limit voltage destortions. It diminishes supply-voltage-flickers and un-balances from the load terminal voltage.

\section{Shunt-Active-Power-Filter}

Sh-APF be a VSI connected in parallel to AC-line, which reacts to clear distortions of current, restores reactive value of I of load and hike the value of p.f of system, which also exhibits dc-link voltage alteration, results to a suitable elimination of rating for dc-capacitors. Responsive current for shunt case is settled utilizing a dynamic-hysteresis-band by adjusting positions of semi conductor switches such that output current flows via reference signal, remains at a predetermined hysteresis-band.

\section{III. 'DC-Capacitors'}

Voltage across capacitors gives individual dc supply voltage for suitable operation of two inverters. By suitable control, dc link voltage reflects as active-reactive sources, thus it over comes the requirement of externaldc-source.2VSI's are required to tie the dc capacitor itself.

\section{CONCLUSION}

This paper presents new technical methods by critical analyzing about problems of power-quality, its consequences and its effects in daily life with suitable measures considering various means. The corrective measures will also elaborated which will be treated as remedial for $\mathrm{PQ}$-issues developed at various levels of equipments. It will support scholars, industry-users as well as distributors of electricity for gaining a suitable guidance by it.

\section{References}

[1] R.C. Dugan, M. F. McGranaghan, S. Santosa,and H.W. Beaty, Electrical Power System Quality, 2 ${ }^{\text {nd }}$ edition, McGraw-Hill, 2002.

[2] Luo,Z.K. Shuai, Z. J. Shen, W. J. Zhu, and X.Y.X Design considerations for maintaining dc-side voltage of hybrid active power filter with Injection circuit,\| IEEE Trans. Power Electron.,vol. 24, no. 1, pp. 75-84, Jan. 2009.

[3] D. Chapman, "Costs of Poor Power Quality", Power Quality Application Guide - Copper Development Association, March 2001.

[4] Anaya-Lara O,Acha E.,"Modeling and Analysis Of Custom Power Systems by PSCAD/EMTDC",IEEE Transactions on Power Delivery, Volume17, Issue: 2002, Pages: 266-272.

[5] Mitigation of voltage sag using Distribution Static Compensator (DSTATCOM) S. Elang Dr.E.Chandra Sekaran, 2011 IEEE.

[6] H. Fujita and H. Akagi, A practical approach to harmonic compensation in power systems: Series connection of passive and active filters,\| IEEE

Trans. Ind. Appl., vol. 27,no. 6, pp. 1020- 1025,Nov./Dec.1991.

[7] R.Mienski, R.Pawelek and I.Wasiak., "Shunt Compensation for Power Quality Improvement Using a STATCOM controller: Modelling and Simulation", IEEE Proce., Vol.151, No.2,March 2004.

[8] J.Nastran, R. Cajhen, M. Seliger, and P.Jereb,"Active Power Filters for Nonlinear AC loads, IEEE Trans.on Power Electronics Volume 9,No.1, PP: 92-96, Jan 2004. 